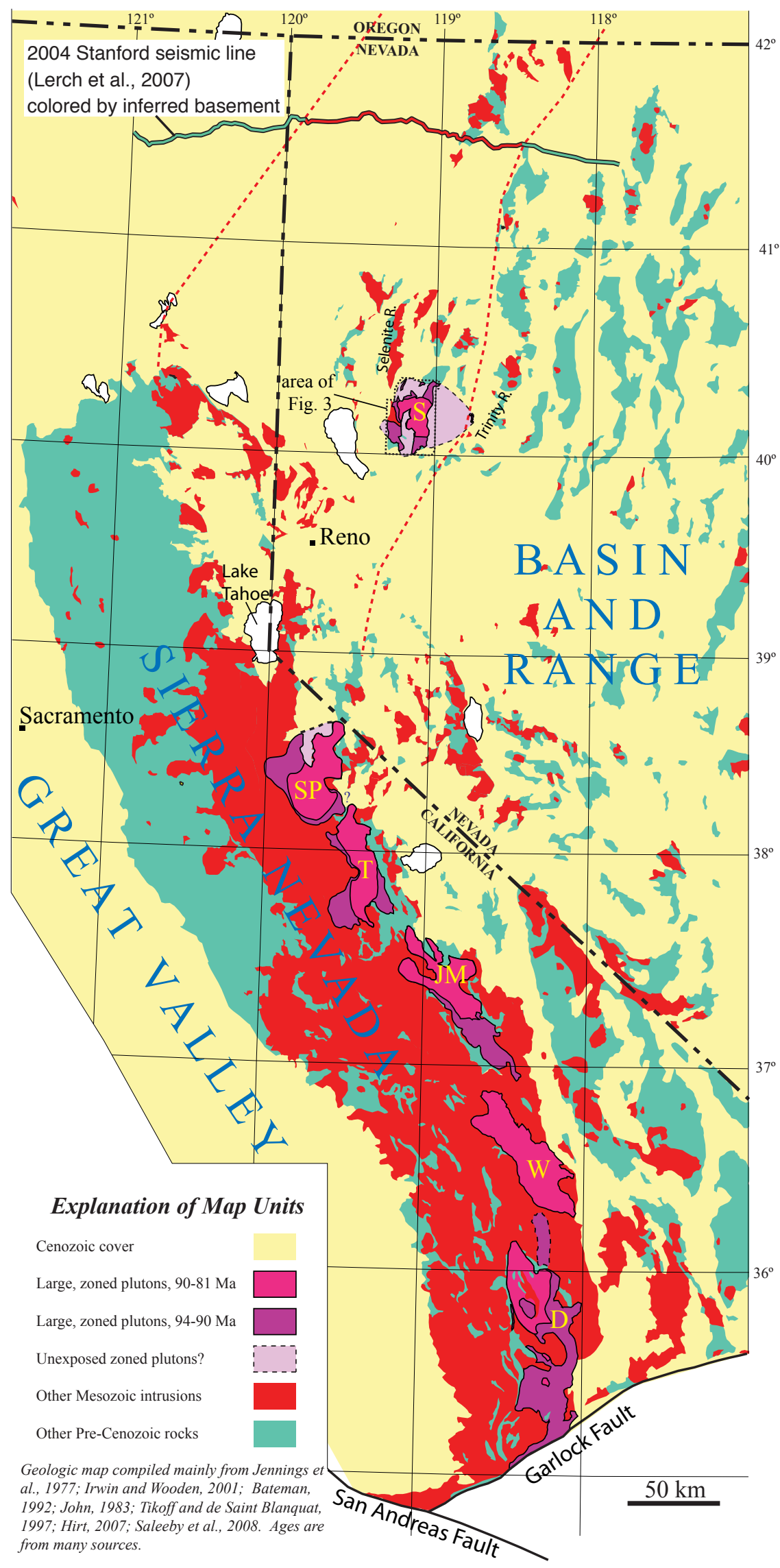




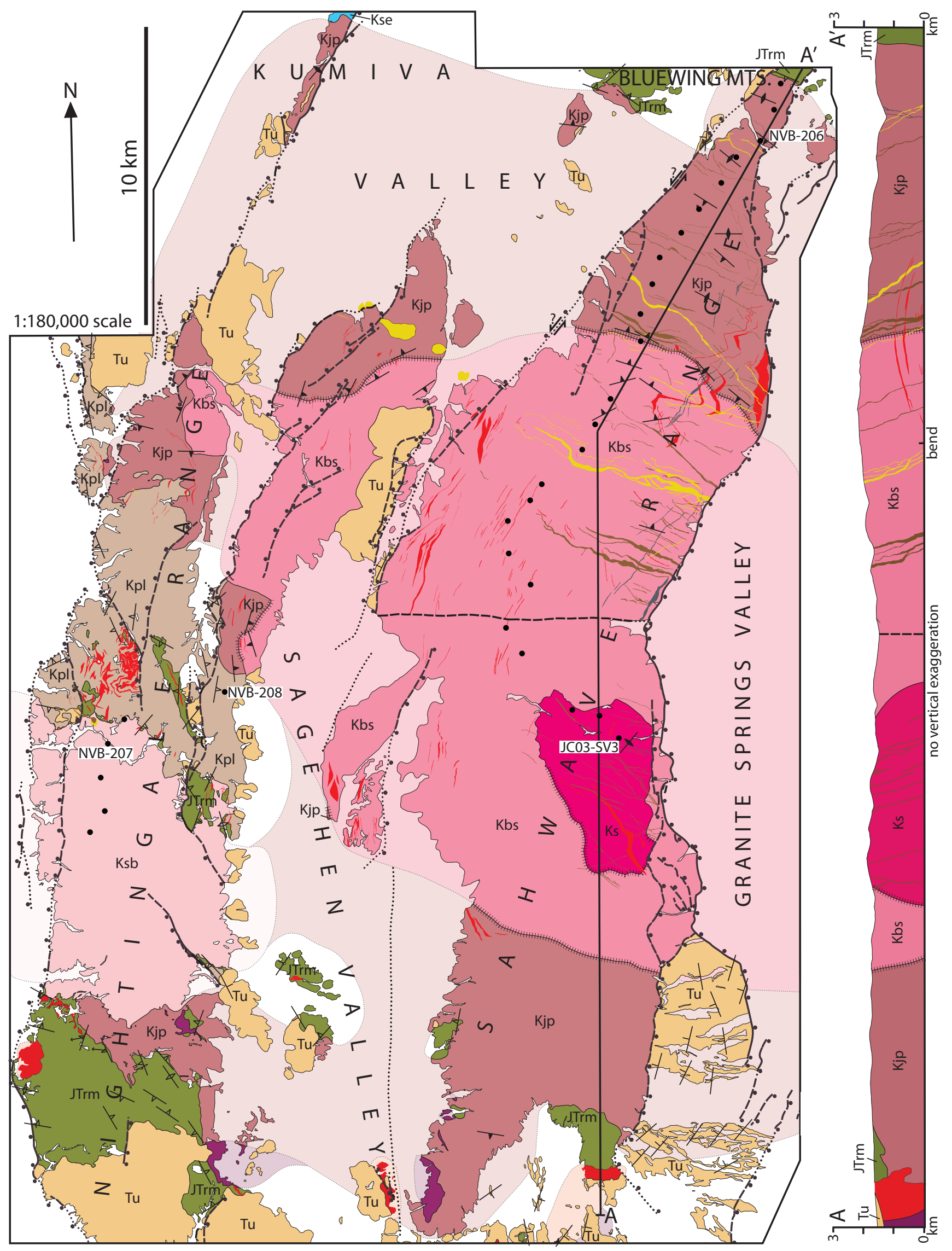


Figure 3B

\section{Map Explanation}

Tertiary

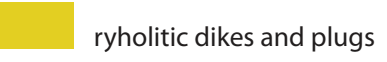

volcanic and sedimentary strata

Cretaceous Sahwave Intrusive Suite

Sahwave Granodiorite

Granodiorite of Bob Spring

School Bus Granodiorite

Granodiorite of Juniper Pass

Selenite Granodiorite

Power Line Intrusive Complex

Auld Lang Syne Group basinal metasedimentary rocks

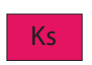

aplite, pegmatite, and leucogranite intrusions (units shown in lighter shade where inferred to underlie valley sediments)

Earlier Mesozoic contact $\Omega$

gradational

contact

concealed contact

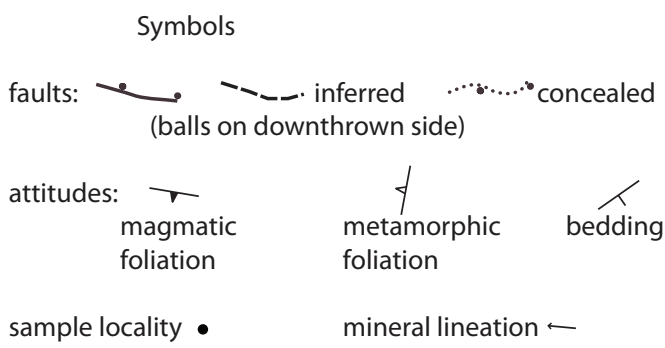




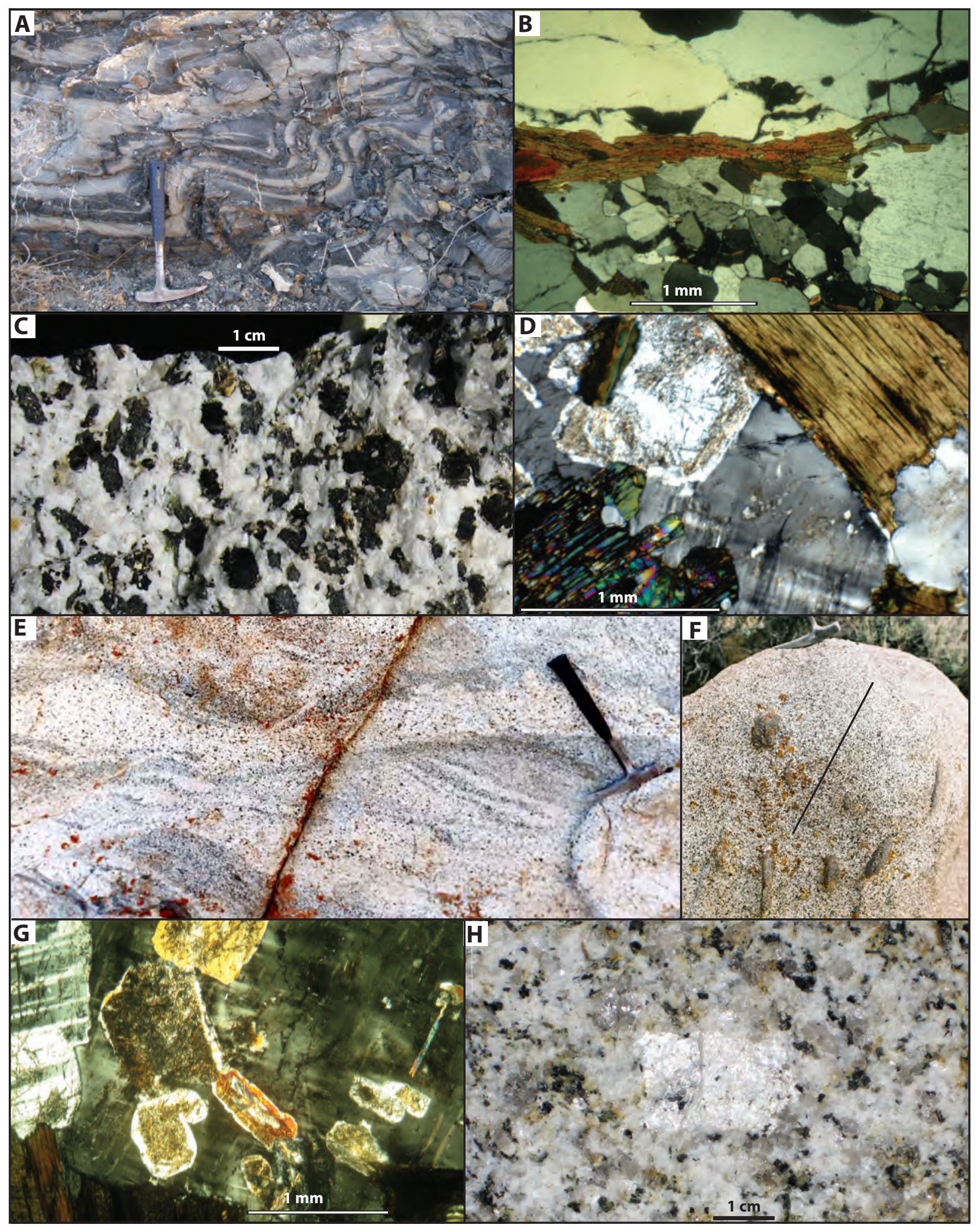




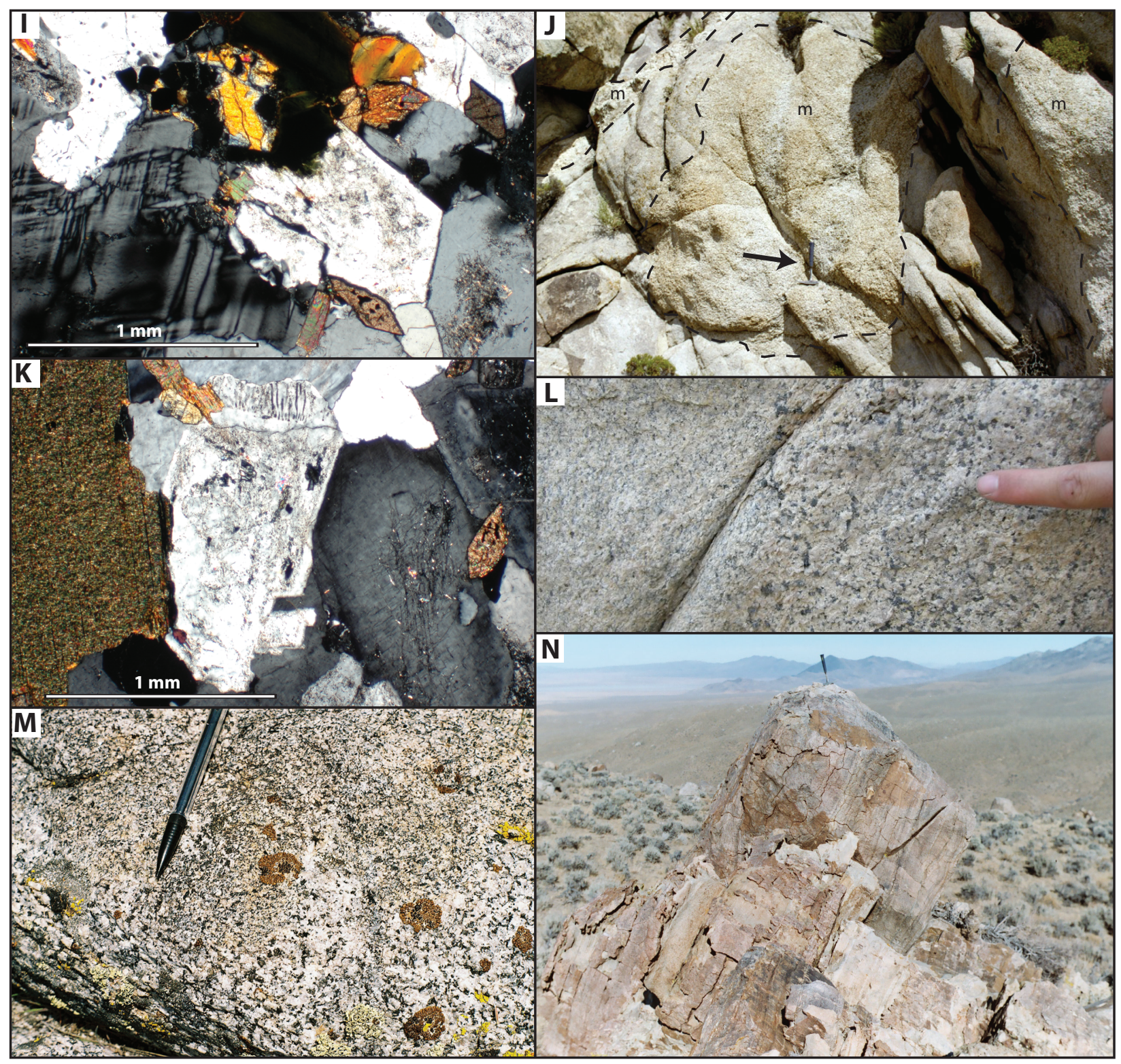




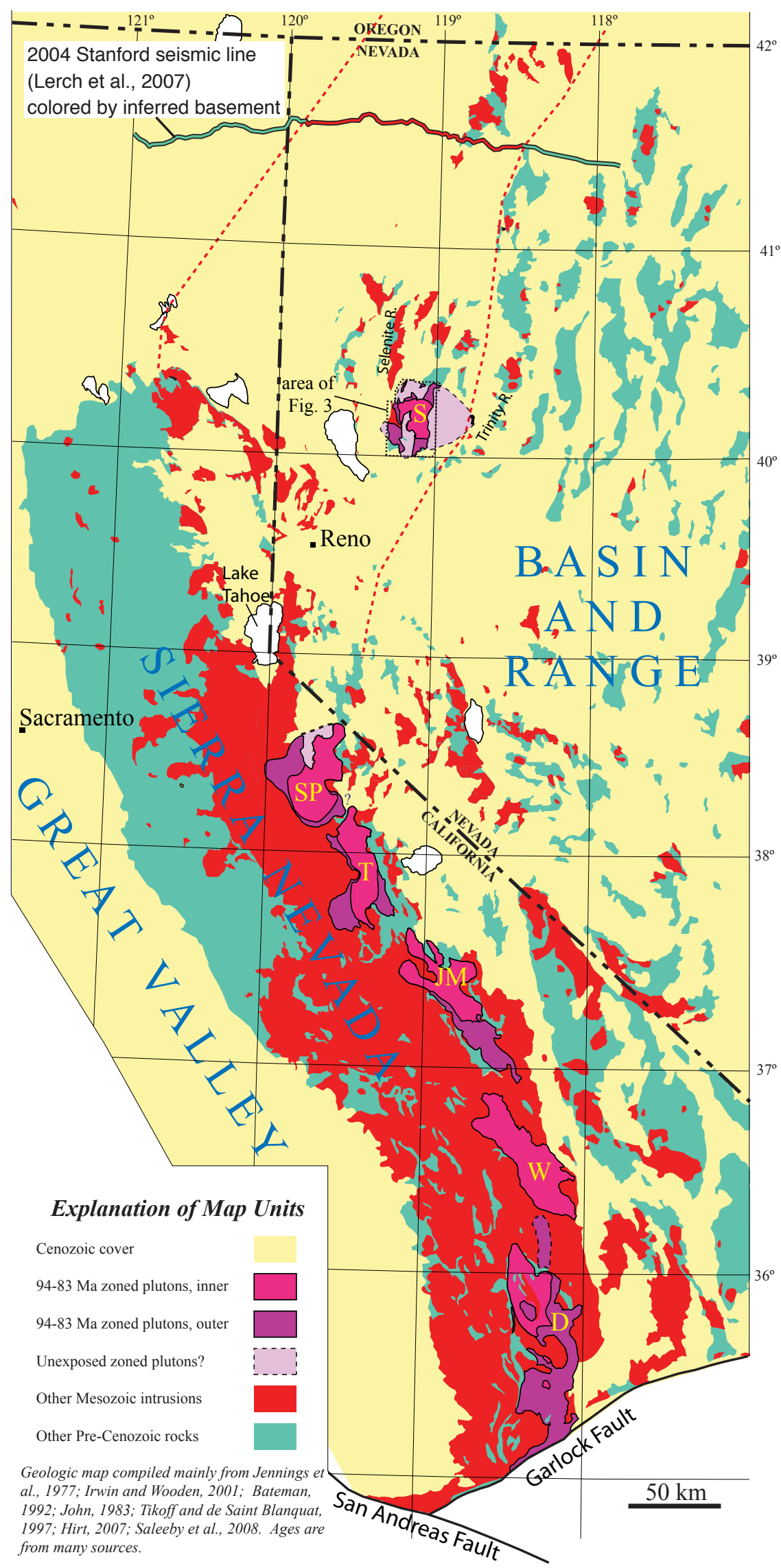

